\section{PTU-117 $\star$ ASSOCIATION OF THE INSULIN-LIKE GROWTH FACTOR 1 MICROSATELLITE WITH PREDISPOSITION TO COLORECTAL CANCER}

doi:10.1136/gut.2011.239301.245

K J Monahan, ${ }^{1,2, *}$ S Spain, ${ }^{3}$ H J Thomas, ${ }^{2}$ I P Tomlinson ${ }^{3}$ Gastroenterology, West Middlesex University Hospital, London, UK; ${ }^{2}$ Cancer Medicine, Imperial College, London, UK; ${ }^{3}$ Molecular and Population Genetics, Cancer Research UK, London, UK

Introduction IGF1 may be important for colorectal cancer risk because of its role in cell growth and differentiation. High IGF1 serum levels have been associated with increased risk of colorectal cancer. Variations in these serum levels have been associated with a CA repeat microsatellite 1 kilobase upstream of the transcription start site. We sought to determine the association of germline variation of the IGFI gene with colorectal cancer predisposition by performing a large case-control study.

Methods Genescan 500 was used to differentiate alleles of the IGF1 microsatellite among 2143 colorectal cancer cases (enriched for family history) and 1715 controls from the CORGI (COloRectal Gene Identification) study, with subsequent $100 \%$ confirmation of about $5 \%$ of genotypes by direct sequencing. Associations of genotypes with the following clinicopathological features were tested: sex; site of tumour; Dukes stage; age of onset; presence of adenomas. Using genotype data obtained from the Hap550 platform by colleagues ${ }^{1}$ plus the genotypes at the insertion/deletion, we reconstructed haplotype blocks around the IGF1 gene in the controls using 68 tagging SNPs.

Results All the alleles confer increased risk for colorectal neoplasia except '192' (192 copies of CA repeat), which is a protective allele (allelic OR for ' 192 ' $=1.199 ; 95 \%$ CI 1.09 to $1.32 ; \mathrm{p}=0.000152)$. The population attributable risk (PAR) for the risk 'allele' (ie, where ' $X$ '=not ' 192 ') is $2.94 \%$. The risk alleles occurred more frequently in more advanced Dukes' stage tumours $\left(p=0.039, \chi^{2}\right)$. Several SNPs in close linkage disequilibrium with IGF1 are also significantly associated with colorectal neoplasia risk.

Conclusion This study demonstrates a novel association of IGF1 microsatellite with colorectal cancer risk. The association is stronger with advanced stage colorectal cancers, and in colonic rather than rectal cancers. This microsatellite is in linkage disequilibrium with other significant SNPs in the promoter region of this gene.

Competing interests K. Monahan Grant/Research Support from: Bobby Moore Fund, S. Spain: None Declared, H. Thomas: None Declared, I. Tomlinson: None Declared. Keywords colorectal cancer, genetics, IGF1.

\section{REFERENCE}

1. Tomlinson I, Webb E, Carvajal-Carmona L, et al. A genome-wide association scan of tag SNPs identifies a susceptibility variant for colorectal cancer at 8q24.21. Nature Genetics 2007. 